\title{
Role of $\mathrm{CT}$ in differentiation between subtypes of lung cancer; is it possible?
}

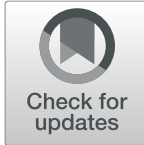

Heba Said Gharraf ${ }^{1 *}$, Sayed Mohamed Mehana² and Mostafa Ali ElNagar ${ }^{3}$

\begin{abstract}
Background: Context and purpose: lung cancer is the second in the incidence rate and the first in death rate in the United States of America in 2017. Its treatment depends upon the tumor staging as well as the histological subtype of lung cancer. CT has been the modality of choice for screening as well as diagnosis of lung cancer; however, few studies tried to correlate different CT features of lung cancer to certain pathological subtypes. Our study aims to assess the CT characteristics of the subtypes of bronchogenic carcinoma.

Results: SQCC shows a higher incidence of central location compared with the rest of the lung cancers (significance level of 50\%, $p$ value of 0.5), internal cavitations (significance level of $94.9 \%, p$ value of less than 0.05 ) as well as more frequency of higher stage within the study population, ADC shows significant predilection to peripheral location compared with the rest of the lung cancers (significance level of $94.9 \%, p$ value of less than 0.05).

Conclusion: There is an evident correlation between the MDCT diagnosis of bronchogenic carcinoma and that of histopathology/cytology. The most common types are SQCC and ADC subtypes. The SQCC type of bronchial carcinoma tends to be central with the internal cavitations are common while ADC tends to be peripheral and solid.

Keywords: Bronchogenic carcinoma, Squamous cell carcinoma, Adenocarcinoma, The Eighth Edition Lung Cancer Stage Classification, Computed tomography, Hilar mass
\end{abstract}

\section{Key points}

- Evaluation of the role of CT in the differentiation of subtypes of bronchogenic carcinoma

- Hilar bronchogenic carcinomas

- Peripheral bronchogenic carcinomas

- Cavitary bronchogenic carcinomas

\section{Background}

According to the American Cancer Society (ACS), lung cancer is the second in the incidence rate and the first in death rate in the United States of America in 2017 [1]. In 2019, over 228,000 adults in the United States will

\footnotetext{
* Correspondence: hebagharraf@gmail.com

${ }^{1}$ Chest Disease Department, Faculty of Medicine, Alexandria University, Alexandria, Egypt

Full list of author information is available at the end of the article
}

have been diagnosed with lung cancer, and lung cancer constitutes approximately $13 \%$ of all new cancer diagnoses. It is estimated that over 76,000 men and over 66,000 women will die of lung cancer in 2019 [2].

In the absence of screening, most patients with lung cancer are not diagnosed until later stages, when the prognosis is poor. The most common symptoms are cough and dyspnea, but the mo3st specific symptom is hemoptysis. Digital clubbing, though rare, is highly predictive of lung cancer. Symptoms can be caused by the local tumor, intrathoracic spread, distant metastases, or paraneoplastic syndromes. Clinicians should suspect lung cancer in symptomatic patients with risk factors [3].

Radiologic manifestations of bronchogenic carcinoma include obstructive pneumonitis or atelectasis, lung

\section{Springer Open}

(c) The Author(s). 2020 Open Access This article is licensed under a Creative Commons Attribution 4.0 International License, which permits use, sharing, adaptation, distribution and reproduction in any medium or format, as long as you give appropriate credit to the original author(s) and the source, provide a link to the Creative Commons licence, and indicate if changes were made. The images or other third party material in this article are included in the article's Creative Commons licence, unless indicated otherwise in a credit line to the material. If material is not included in the article's Creative Commons licence and your intended use is not permitted by statutory regulation or exceeds the permitted use, you will need to obtain permission directly from the copyright holder. To view a copy of this licence, visit http://creativecommons.org/licenses/by/4.0/. 
nodule or mass, apical mass, cavitated mass, or nodule or mass associated with lymphadenopathy [4].

The initial study should be chest $\mathrm{x}$-ray, it is readily available and inexpensive but if results are negative and suspicion remains, the clinician should obtain a computed tomography scan with contrast. Tissue samples should be obtained using the least invasive method possible [3].

CT of the chest is an important informative tool that helps in detailed imaging of the primary tumor and its anatomic relationship to other structures, and it provides information with respect to the size of mediastinal lymph nodes and the status of the pleural space. However, CT criteria for adenopathy are based on size alone and do not always accurately reflect the presence or absence of tumor metastases. CT can best be thought of as a technique that provides a roadmap for more accurate surgical staging [5].

The World Health Organization (WHO) classification applies to the surgically resected malignant tumors of the lung and pleura [1]. Primary carcinomas of the lung are traditionally classified as either small cell lung cancer (SCLC) or non-small cell lung cancer (NSCLC). NSCLC constitutes approximately $80 \%$ of all primary lung cancers with adenocarcinoma, squamous cell carcinoma (SCC), and large cell carcinoma constituting the major histological types [6, 7].

As treatment depends upon the tumor staging as well as histological subtype of lung cancer [5] and since CT has been the modality of choice for screening as well as diagnosis of lung cancer, recently few studies tried to correlate different $\mathrm{CT}$ features of lung cancer to certain pathological subtypes.

Because these CT features have not been fully investigated, the purpose of our research was to compare the clinical pathology with different morphologic CT features.

\section{Objectives}

Assess the CT characteristics of the subtypes of bronchogenic carcinoma.

\section{Methods}

Data were retrospectively collected from high-resolution CT scans of 38 patients diagnosed as lung cancer from January to September 2018 in the Radio-diagnosis Department of Medical Research Institute. These patients underwent diagnostic pathological biopsy either $\mathrm{CT}$ in peripherally located lesions or bronchoscopic guided in central lesions.

\section{CT protocol and image analysis}

The CT scans were obtained on Siemens Emotion 16 multi-detector CT (MDCT) using volumetric High- spatial-frequency kernel algorithm with slice thickness of 1-1.25 mm, table speed for volumetric HRCT to enable the least cycles of breath-holds as possible, mean tube rotation of $0.75 \mathrm{~s}$, collimation $1 \mathrm{~mm}$, pitch 1.5, helical mode (volumetric HRCT), field of view (FOV) for small, medium, and large patients, $\mathrm{kVp}$ and $\mathrm{mA}$ per slice: 140 for each. For adequate multi-planar reconstruction, scans were performed to cover the root of the neck down to the level of the adrenal gland. Then, the images acquired were sent to a separate workstation (OsiriX V. $8.5)$ to be processed, manipulated, and reconstructed.

Multi-planar, as well as multiple intensity projection (MIP) reconstruction methods, had been done.

Using the blind technique, two radiologists with 12 and 15 years of experience fully revised and analyzed the thin-section CT scan findings including location (central or peripheral), size, shape, margin, involved lobe and the presence or absence of degeneration and cavitations, consolidation/atelectasis, air broncho-gram, nodal metastasis, vessel amputation, pleural/mediastinal infiltration, satellites and distant metastasis including suprarenal, liver and bone. Staging of the tumors was done following the eighth edition TNM stage classification for lung cancer [8].

\section{Statistical analysis}

The study population included 35 male patients (92.1\%) and 3 female patients (7.9\%).

From the study population, 17 cases were pathologically proven as squamous cell carcinoma (SQCC) (44.7\%) (Fig. 1), 12 were adenocarcinoma (ADC) (31.6\%) (Figs. 2 and 3), the remainder 9 cases (Fig. 4) were pathologically proven to be anaplastic type (two cases), small cell carcinoma (SCC) (two cases), large cell carcinoma (two lesions), carcinoid tumor (two lesions) and lung sarcoma (one lesion) (Fig. 5).

The age of the study population ranged from 38 to 71 years with a mean of $55+/-9.2$ years, no significant difference regarding the age was noted between the various pathological types of the study population with the mean age for squamous cell carcinoma patients was $55=/-10$ while that for the adenocarcinoma patients was $59.5+1$ -8.3 years.

The size of the lesions in the current study ranges from 1.6 to $25 \mathrm{c}$ with mean size of $7.1+/-4.5 \mathrm{~cm}$, squamous cell carcinoma lesions were larger than adenocarcinoma lesions with a mean size of $7.7+/-2.7$ $\mathrm{cm}$ versus $5.5+/-2.3 \mathrm{~cm}$ respectively (Table 1 ).

Regarding the location of the lesion, the right upper lobe was the most encountered location with 15 lesions followed by the right lower lobe (9 lesions) then the left upper (7lesions ), left lower lobe (4 lesion), and the right middle lobe (one lesion) while one lesion was diffusely infiltrating the right lung (lung sarcoma). 

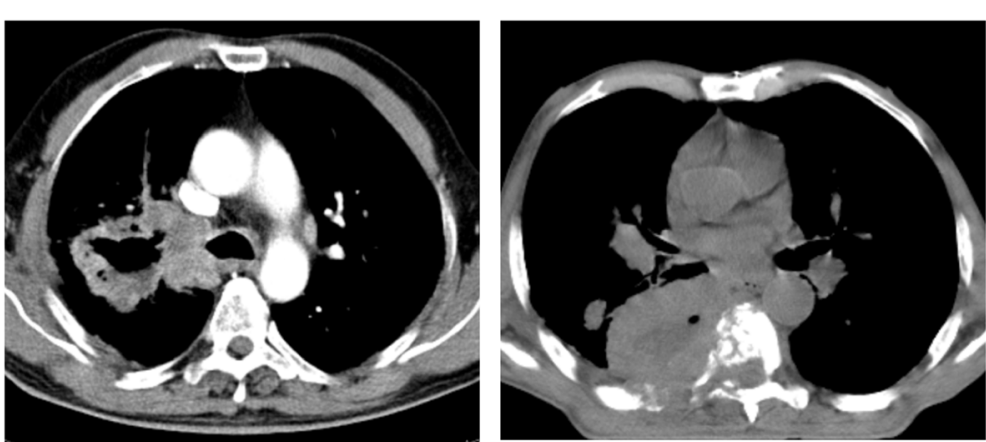

a.

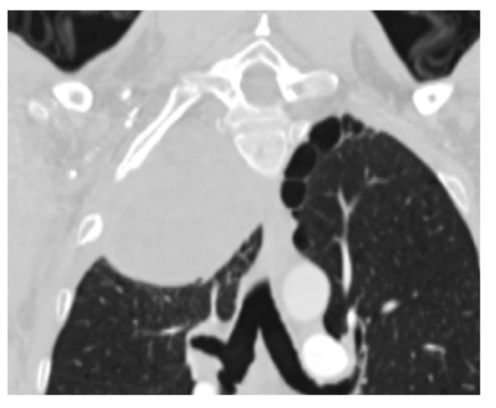

c. b.

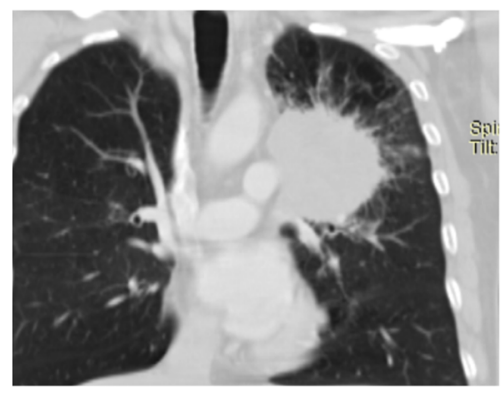

d.

Fig. 1 Four different cases of squamous cell carcinoma. a shows the classical CT appearance with thick walled central hilar cavitary lesion. b shows a peripheral thick cavitary lesion with invasion of the pleura, chest wall, and the posterior mediastinum. $\mathbf{c}$ shows a superior sulcus tumor with invasion of the chest wall (not shown) and $\mathbf{d}$ shows a speculated lung parenchymal mass lesion separable from the hilum (not shown) invading the mediastinum

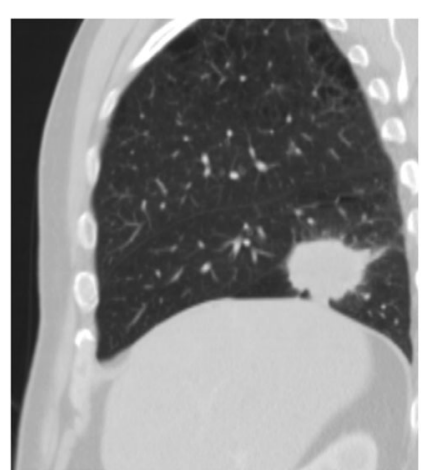

a.

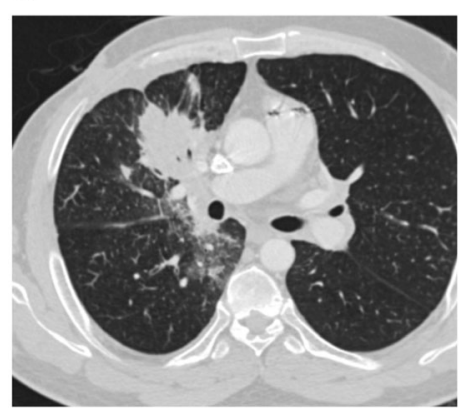

c.

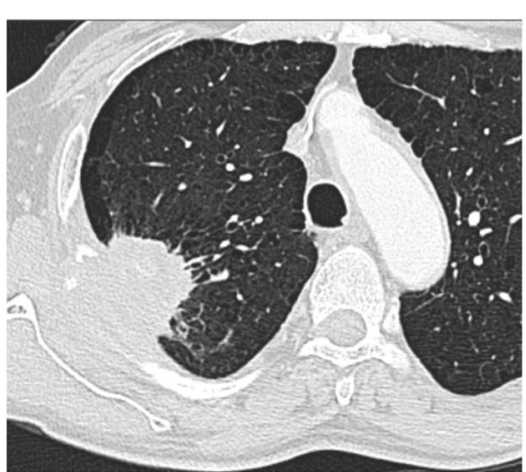

b.

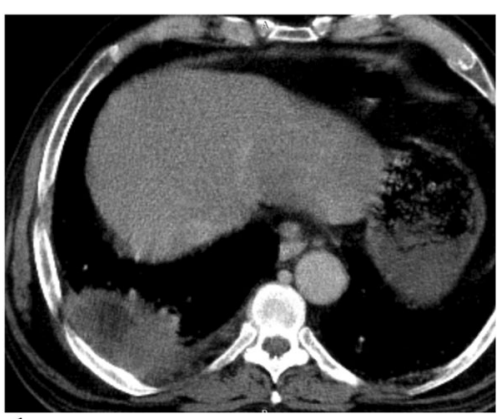

d.

Fig. 2 Four different cases of right-sided adenocarcinoma. $\mathbf{a}, \mathbf{b}$, and $\mathbf{c}$ show the classical solid speculated mass lesion with pleural and chest wall invasion in image $\mathbf{b}$, bronchial invasion in image $\mathbf{c}$. In image $\mathbf{d}$, the lesion is thick-walled cavitary lesion with pleural invasion 


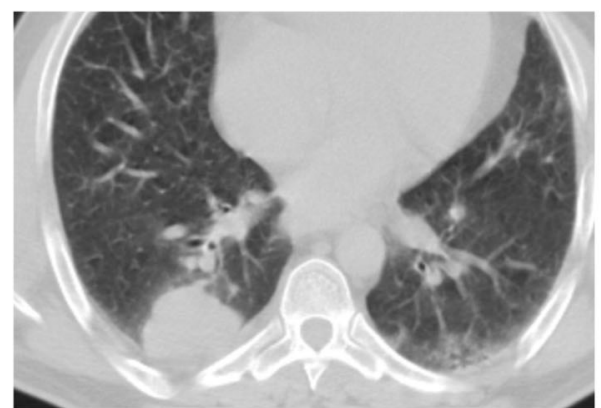

a.

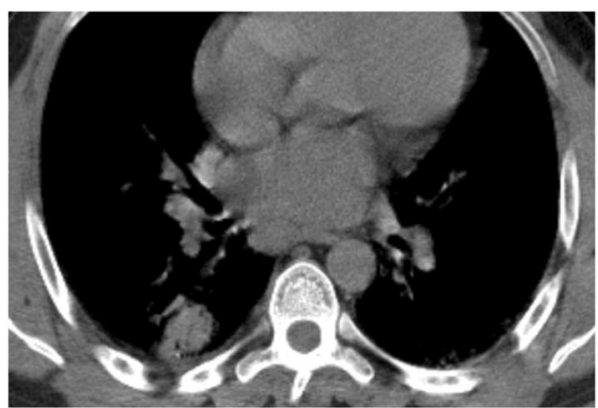

b.

Fig. 3 Pathologically proven invasive mucinous adenocarcinoma (formally described as BAC). Image a show a well-defined pleural-based solid peripheral lesion, image $\mathbf{b}$ in a higher cut show an internal air bronchogram within the lesion

SQCC shows a higher incidence of central location (64\%) compared with the rest of the lung cancers (9.5\%) (significance level of $50 \%, p$ value of 0.5 ) with the remainder central lesions were SCC and a single ADC (Table 1).

ADC shows significant predilection to a peripheral location (91.6\%) compared with the rest of the lung cancers (9.5\%) (significance level of $94.9 \%, p$ value of less than 0.05) (Table 1).

Internal cavitations were noted in $47 \%$ of SQCC compared with $4 \%$ to the rest of lung cancers cases (significance level of 99.8\%, $p$ value of less than 0.002); in addition to these lesions, only one ADC was cavitary, the rest of the lesions were essentially solid; however, in the larger ones, there was internal cystic degeneration with peripheral air broncho-gram in the lesion proved to be invasive mucinous adenocarcinoma (Table 1).

In the current study, staging was done using The Eighth Edition Lung Cancer Stage Classification [9]. Mediastinal and pleural invasion was considered when the tumor tissue is seen within the mediastinal fat or within the pleural cavity, wide contact with either the

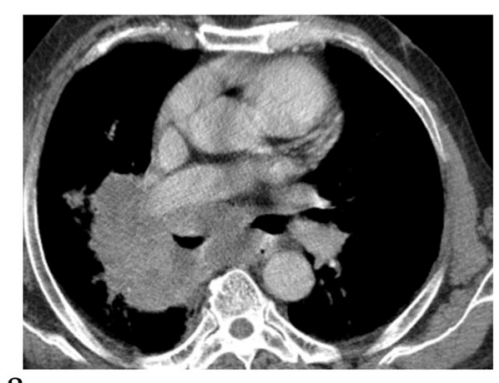

a.

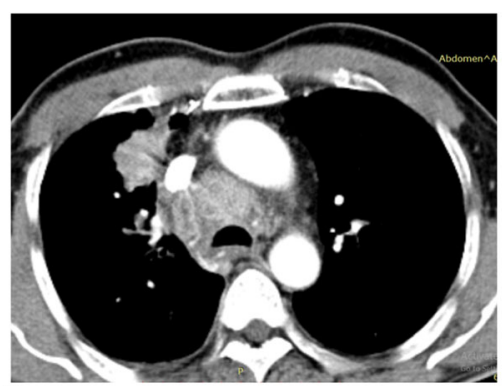

c.

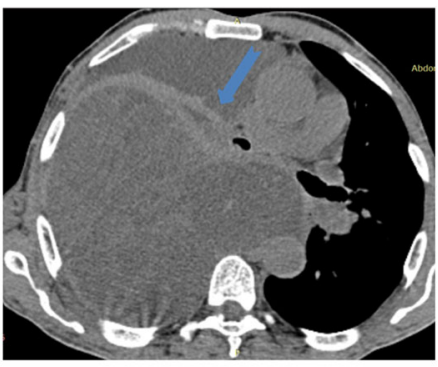

b.

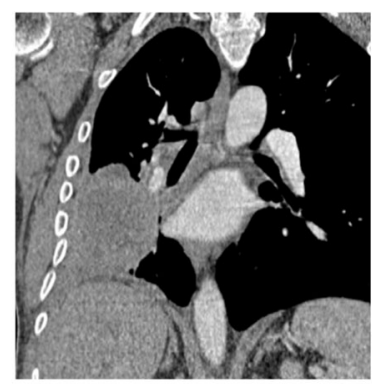

d.

Fig. 4 Four different tumors in the current study. a Small cell carcinoma appearing as a hilar mass showing internal necrosis, encasing the main bronchus with direct invasion of the mediastinum. $\mathbf{b}$ Lung sarcoma manifested as low attenuation mass lesion occupying the right hemithorax with the involvement of the mediastinum and pleura, the right lung is seen collapsed (arrow) with the mediastinum is seen displaced to the contralateral side. $\mathbf{c}$ Large cell carcinoma is shown as a lobulated soft-tissue attenuation mass lesion with loss of clear line of cleavage with the mediastinum and sizable mediastinal nodes. $\mathbf{d}$ Carcinoid tumor is shown as a well-defined homogeneous lesion with inseparability from the pleura extending to the hilum with infiltration of the middle lobe bronchus (not shown) 


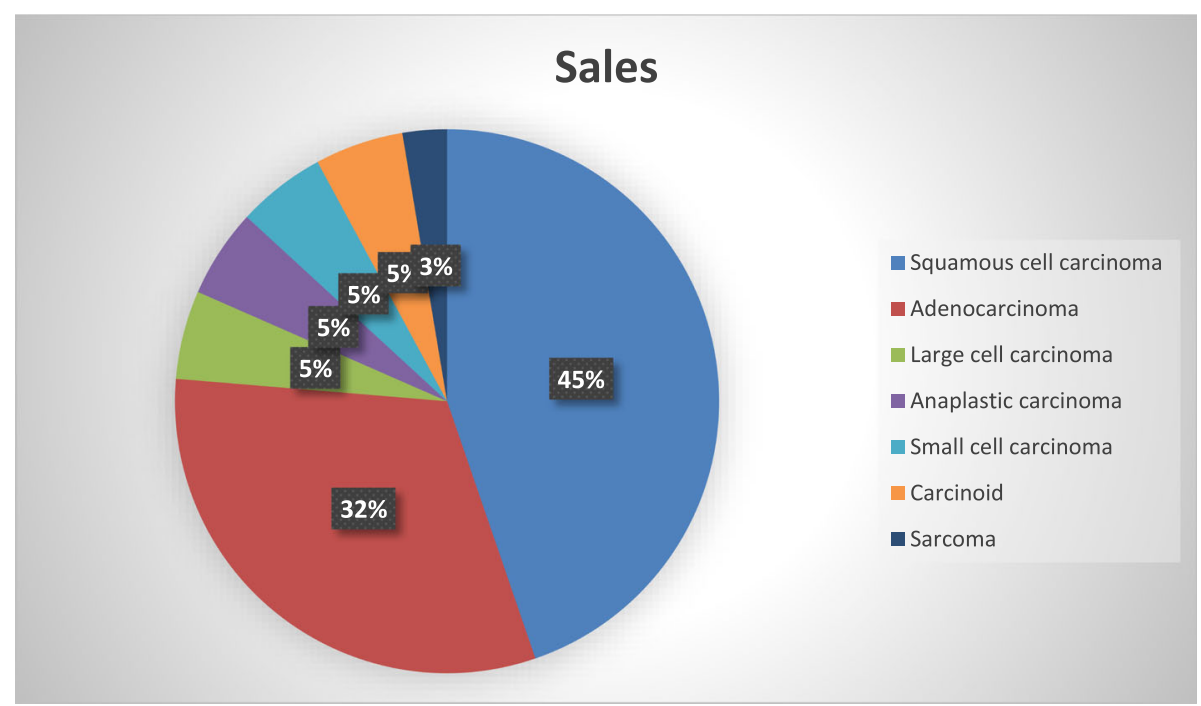

Fig. 5 Study population

mediastinum or pleura (probable invasion) was not considered invasion in the statistical analyses nor staging.

Regarding the local staging of the lesions, SQCC has a higher incidence of $\mathrm{T} 4$ (70\%) compared with the other types apart from SCC (the two included cases were T4); however, the difference was not significant (Table 2).

No significant statistical difference was noted regarding the pathological mediastinal nodes, pulmonary nor distant metastases between the different tumor types (Table 2).

\section{Discussion}

Lung cancer kills more patients than any other malignancy in the world [10]. Histopathological analysis is the gold standard for diagnosing lung cancer and defines the cancer types. It is crucial to delineate lung malignancy from its morphologic mimic as specific treatment modalities (including surgical resection, chemotherapy, radiotherapy, and targeted therapy) can limit the progression of the disease and improve the survival outcomes of the patients [11].

SQCC was the most common subtype encountered in the current study followed by ADC accounting for $45 \%$ and $32 \%$ respectively, the distinction between them is critical for selecting the optimal treatment [12].

In the literature, SQCC is the most common subtype of bronchial carcinoma; however, the incidence of ADC is increasing, also 11 studies reviewing earlier diagnoses

Table 1 The size of the lesions

\begin{tabular}{|c|c|c|c|c|c|c|c|c|}
\hline \multirow[t]{2}{*}{ Pathological type } & \multirow{2}{*}{$\begin{array}{l}\text { Mean } \\
\text { Size } \\
(\mathrm{cm})\end{array}$} & \multicolumn{2}{|l|}{ Location } & \multicolumn{2}{|c|}{ Morphology } & \multicolumn{3}{|c|}{$\begin{array}{l}\text { Direct invasion } \\
\text { (Multiple direct invasion was seen in some cases) }\end{array}$} \\
\hline & & Central & Peripheral & Cavitary & Solid & Pleura & Mediastinum & Chest wall \\
\hline $\begin{array}{l}\text { Squamous cell carcinoma } \\
\text { (17 cases) }\end{array}$ & $\begin{array}{l}7.7 \\
+/- \\
2.7\end{array}$ & 11 & 6 & 8 & 9 & 11 & 10 & 3 \\
\hline $\begin{array}{l}\text { Adeno-carcinoma } \\
\text { (12 cases) }\end{array}$ & $\begin{array}{l}5.5 \\
+/- \\
2.3\end{array}$ & 1 & 11 & 1 & 11 & 4 & 3 & 2 \\
\hline $\begin{array}{l}\text { Anaplastic carcinoma } \\
\text { ( } 2 \text { cases) }\end{array}$ & 4.5 & & 2 & & 2 & 1 & & \\
\hline $\begin{array}{l}\text { Sarcoma } \\
\text { (one case) }\end{array}$ & 25 & Diffuse & & & 1 & 1 & 1 & \\
\hline $\begin{array}{l}\text { Small CELL Carcinoma } \\
\text { (two case) }\end{array}$ & 10 & 1 & 1 & & 1 & 1 & 2 & 1 \\
\hline $\begin{array}{l}\text { Large cell carcinoma } \\
\text { (two case) }\end{array}$ & 3 & & 2 & & 2 & & 1 & \\
\hline $\begin{array}{l}\text { Carcinoid } \\
\text { (two cases) }\end{array}$ & 7.5 & & 2 & & 2 & 2 & & \\
\hline
\end{tabular}


Table $\mathbf{2}$ Local staging of the lesions

\begin{tabular}{|c|c|c|c|c|c|c|c|c|c|}
\hline & \multicolumn{4}{|c|}{ T staging } & \multicolumn{5}{|c|}{ Metastases } \\
\hline & $\mathrm{T1}$ & $\mathrm{T} 2$ & T3 & $\mathrm{T4}$ & Nodal & Lung & Bone & Liver & Adrenal \\
\hline Squamous cell carcinoma (17 cases) & & 1 & 4 & 12 & 7 & 6 & 5 & 1 & 1 \\
\hline $\begin{array}{l}\text { Adeno-carcinoma } \\
\text { (12 cases) }\end{array}$ & 1 & 3 & 4 & 4 & 5 & 2 & 3 & & \\
\hline Anaplastic carcinoma (2 cases ) & 1 & & & 1 & 1 & & 1 & & \\
\hline $\begin{array}{l}\text { Sarcoma } \\
\text { (one case) }\end{array}$ & & & & 1 & & & & & \\
\hline $\begin{array}{l}\text { Small cell } \\
\text { carcinoma } \\
\text { (two cases) }\end{array}$ & & & & 2 & 2 & & 1 & 1 & \\
\hline $\begin{array}{l}\text { Large cell } \\
\text { carcinoma } \\
\text { (two cases) }\end{array}$ & & 2 & & & 1 & & & & \\
\hline $\begin{array}{l}\text { Carcinoid } \\
\text { (two cases) }\end{array}$ & & & 2 & & 2 & & & & \\
\hline
\end{tabular}

increased ADC by $30 \%$ overall. This may be due to changes in the diagnostic criteria and changes in bronchial carcinoma classifications [13]. Moreover, Zhang et al. [14] found in their study based on data of 658 primary lung cancer patients that ADC was the most common subtype followed by SQCC then SCC, the proportion of ADC increased from 25.93 (1995-1997) to $56.36 \%$ (2013-2015). The number of SQCC cases increased from 710 (1995-1997) to 3050 (2013-2015); however, the proportion decreased from 49.1 to $26.34 \%$.

Among the current study population, 13 lesions were central in location (34.2\%) from which 11 were SQCC, one ADC, and one SCC.

In the literature, the incidence of central of SQCC is well known in many studies including Mizushima et al. [15] who found in their study over 235 squamous cell carcinomas that 129 was peripheral and 106 were central and William Krimsky et al. [16] found a total of 56 patients were diagnosed with SCC. Of these, $55 \%(n=31)$ had peripheral and $45 \%(n=25)$ had central SCC.

Mismatching results were documented in the study by Zhe et al. [17] were in 302 consecutive patients included 99 patients were ADC, 95 patients with SQCC, and 108 patients with SCLC with ADC were more aggressive.

Regarding the SCC, Dongiun et al. [18] in his study on 142 lesions, 121 from 142 lesions to be central from which 112 lesions invade the mediastinum.

Internal cavitations were noted in 9 cases of the current study population including 8 SQCC and a single ADC. Matching results were described by Chaudhuri et al. [19] who found in their study on 100 cavitary lesions that 82 were SQCC, 11 undifferentiated carcinomas of large polygonal-cell type, and seven ADC.

In the 2011 classification [20], ADC was divided into pre-invasive types including atypical adenomatous hyperplasia and ADC in situ, minimally invasive, and invasive types. Pre-invasive types appear on CT commonly as ground-glass attenuation, minimally invasive and invasive types commonly appear with the solid invasive component that varies in size (histologically in noninvasive it is less than $5 \mathrm{~mm}$ and in invasive type, it is more than $5 \mathrm{~mm}$ ) [21].

Other CT features of ADC were described in the literature including cavitations, calcification, consolidations, and scar-like appearance [22].

$\mathrm{ADC}$ in the current study was noted in 11 peripheral lesions and one central lesion, all these lesions were invasive type with two of them showing anaplastic transformation. Radiologically, one lesion was cavitary, 11 were solid and there was a rim of ground-glass attenuation noted around 5 of the lesions reflecting bronchoalveolar components; the solid lesions included 6 with speculated appearance, one was stellate like three shows lobulated margins, and one with peripheral air bronchogram proven pathologically to be invasive mucinous adenocarcinoma (formally was described as bronchoalveolar carcinoma (BAC) ) [23].

The current study included two carcinoid tumors, both were large lesions with lobar endobronchial extension, Our findings match with the data in the literature as most of the larger studies [24, 25] of pulmonary carcinoid tumors have found that $85 \%$ of lesions arise within the central airways as endobronchial masses, aside from an article by Magid et al. [26] in 1989 and Quinn et al. in 2011 [27].

In the current study, two large cell carcinomas were included, both were solid and peripheral in location with no evident pleural involvement. In the literature, Oshiro et al. found in his study on 38 clear cell carcinoma lesions that 32 lesions were peripheral and 6 lesions were central in location, the mean size of the lesions was $3.2 \mathrm{~cm}$ with lobulated outlines and 
homogeneous solid nature apart from cystic necrosis in larger tumors [28].

A single sarcoma was included in the current study, and it was a large solid lesion inseparable from the pleura and mediastinum and occupying most of the right hemithorax. Limited studies noted in the literature on the lung sarcoma with Duran et al. [29] found in his study on 7 lesions that lung sarcomas are large and homogeneous.

\section{Conclusion}

There is an evident correlation between the MDCT diagnosis of bronchogenic carcinoma and that of histopathology/cytology. The most common types are SQCC and ADC subtypes. The SQCC type of bronchial carcinoma tends to be central with the internal cavitations are common while ADC tends to be peripheral and solid.

\section{Acknowledgements}

Not applicable.

\section{Authors' contributions}

HG: follow-up for the medical issues of the patients, clinical data, and bronchoscope tissue biopsies as well as writing the manuscript. She is the corresponding author. SM: supervising the study, analyzing the radiological findings, revising, and assessing the radiological issues of the study. ME: cases selection, prescribing the chemotherapy. All authors have read and approved the manuscript.

\section{Funding}

The author state that this work has not received any funding.

\section{Availability of data and materials}

The datasets used and/or analyzed during the current study are available from the corresponding author on reasonable request.

\section{Ethics approval and consent to participate}

This study was approved by the Ethics Committee of the medical research institute- Alexandria University on 9/10/2019; Reference number of approval: IORG0008812. All patients included in this study gave written informed consent to participate in this research (all the patients were older than 16 years old).

\section{Consent for publication}

All patients included in this research gave written informed consent to publish the data contained within this study.

\section{Competing interests}

The author of this manuscript declares no relationships with any companies, whose products or services may be related to the subject matter of the article.

\section{Author details}

${ }^{1}$ Chest Disease Department, Faculty of Medicine, Alexandria University, Alexandria, Egypt. ${ }^{2}$ Department of Diagnostic and Intervention Radiodiagnosis, Medical Research Institute, Alexandria University, Alexandria, Egypt. ${ }^{3}$ Department of Oncology, Medical Research Institute, Alexandria University, Alexandria, Egypt.

Received: 7 May 2020 Accepted: 27 August 2020

Published online: 17 September 2020

\section{References}

1. American cancer society. cancer facts and figures 2017 [cited 2018].

2. Lung cancer-non-small cell: statistics. Cancer.Net Editorial Board, 2019

3. X KM Latimer. lung cancer: clinical presentation and diagnosis.(2018). FP essentials, 2018 -:464:23-26.

4. Jiang B, Takashima S, Miyake C, Hakucho T, Takahashi Y, Morimoto D et al (2014) Thin-section CT findings in peripheral lung cancer of $3 \mathrm{~cm}$ or smaller: are there any characteristic features for predicting tumor histology or do they depend only on tumor size? Acta radiologica 55(3):302-308

5. Mazzone PJ, Silvestri GA, Patel S et al (2018) Screening for lung cancer: chest guideline and expert panel report. Chest 153(4):954-985

6. Fong KM, Bowman RV, Fielding D, et al. Queensland integrated lung cancer outcomes project (qilcop): initial accrual and preliminary data from the first 30 months. (2003). Respirology;8Suppl: A53.

7. American Cancer Society. Cancer facts and figures 2008. Atlanta, Ga: American Cancer Society; 2008

8. Rami-Porta R, Bolejack V, Giroux D et al (2014) The IASLC lung cancer staging project: the new database to inform the eighth edition of the TNM classification of lung cancer. J Thorac Oncol 9:1618-1624

9. Detterbeck FC, Boffa DJ, Kim AW, Tanoue LT. The Eighth Edition Lung Cancer Stage Classification. (2017). Chest. Jan;151(1):193-203.

10. Jemal A, Bray F, Center MM, Ferlay J, Ward E et al (2011) Global cancer statistics. CA Cancer J Clin 61:69-90

11. Travis WD, Brambilla E, Riely GJ. New pathologic classification of lung cancer: relevance for clinical practice and clinical trials. Journal of clinical oncology. (2013). Official journal of the American Society of Clinical Oncology; 31: 992-1001.

12. Molina JR, Yang P, Cassivi SD et al (2008) Non-small cell lung cancer: epidemiology, risk factors, treatment, and survivorship. Mayo Clinic proceedings 83:584-594

13. Cecilia Zappa and Shaker A. Mousa. Non-small cell lung cancer: current treatment and future advances. (2016). Transl Lung Cancer Res. Jun; 5(3): 288-300.

14. Zhang $X$, Wu L, Xu Y et al (2018) Trends in the incidence rate of lung cancer by histological type and gender in Sichuan, China, 1995-2015: A single-centre retrospective study. Thoracic Cancer 9:532-541

15. Mizushima Y, Yamashita R, Kusajima Y, Sugiyama S. Prognostic comparison between peripheral and central types of squamous cell carcinoma of the lung in patients undergoing surgical resection. (2000). Oncol Rep. Mar-Apr; 7(2):319-322.

16. William Krimsky, Nargiz Muganlinskaya, Saiyad Sarkar, et al. The changing anatomic position of squamous cell carcinoma of the lung - a new conundrum. (2016). J Community Hosp Intern Med Perspect; 6(6)

17. Zhe Wang, Minghuan Li, Yong Huang et al. Onco Targets. (2018) Ther; 11: 2509-2517.

18. Dongjun Lee, MD, Ji Young Rho, MD, Seunghun Kang, et al . CT findings of small cell lung carcinoma. Can recognizable features be found? (2016) Medicine (Baltimore). Nov; 95(47): e5426

19. Chaudhuri MR (1973) Primary pulmonary cavitating carcinomas. Thorax 28:354-366

20. William D. Travis, MD, Elisabeth Brambilla, et al. International Association for the Study of Lung Cancer/American Thoracic Society/European Respiratory Society International Multidisciplinary Classification of Lung Adenocarcinoma. (2011). Journal of Thoracic Oncology • Volume 6, Number 2.

21. Gardiner N, Jogai S, Wallis A (2014) The revised lung adenocarcinoma classification_an imaging guide. J Thorac Dis 6(S5):S537-S546

22. Heather M Pascoe, Henry C Knipe, Diane Pascoe, Stefan B Heinze. The many faces of lung adenocarcinoma: A pictorial essay. (2018). J Med Imaging Radiat Oncol. Volume62, Issue5. October, Pages 654-661

23. Austin JH, Garg K, Aberle D, Yankelevitz D et al (2013) Radiologic implications of the 2011 classification of adenocarcinoma of the lung. Radiology 266:62-71

24. Modlin IM, Lye KD, Kidd M (2003) A 5-decade analysis of 13,715 carcinoid tumours. Cancer 97:934-959

25. Davila DG, Dunn WF, Tazelaar HD et al Bronchial carcinoid tumours. (1993). Mayo Clin Proc 68:795-803

26. Magid D, Siegelman SS, Eggleston JC et al (1989) Pulmonary carcinoid tumours: CT assessment. J Comput Assist Tomogr 13:244-247

27. Meisinger QC, Klein JS, Kelly J et al (2011) CT Features of Peripheral Pulmonary Carcinoid Tumors. American Journal of Roentgenology 197:1073-1080

28. Oshiro Y, Kusumoto M, Matsuno $Y$ et al (2004) CT findings of surgically resected large cell neuroendocrine carcinoma of the lung in 38 patients. AJR Am J Roentgenol 182(1):87

29. Duran-MendicutiA CP, Vargas SO (2003) Primary synovial sarcoma of the chest: radiographic and clinicopathologic correlation. J Thorac Imaging 18(2):87-93

\section{Publisher's Note}

Springer Nature remains neutral with regard to jurisdictional claims in published maps and institutional affiliations. 